\title{
Liverwort Control: An Ancillary Role for Ozone-based Irrigation Water Treatment Systems?
}

\author{
Thomas Graham ${ }^{1}$ and Michael A. Dixon \\ School of Environmental Sciences, University of Guelph, Guelph, Ontario \\ N1G 2W1, Canada
}

\section{Additional index words. Marchantia polymorpha, nursery, water recycling}

\begin{abstract}
Marchantia polymorpha L. (a thalloid liverwort) is a common plant pest in nursery and greenhouse production systems. The rapid growth and dissemination of this pest can result in heavy mats of thallus tissue on the surface of pots, which restrict water penetration, compete for nutrients, and provide a habitat for other pests and disease vectors. The sensitivity of liverwort to aqueous ozone was examined to determine if routine use of ozone, as a component of an irrigation water remediation strategy, could provide ancillary services in the form of liverwort management. Three experiments were performed to evaluate contact time (CT) thresholds and application frequencies suitable for liverwort management applications. The first two experiments confirmed that $\mathrm{CT}$ is a suitable process control parameter with a base liverwort management threshold occurring between $C T$ T 0.84 and $1.68 \mathrm{mg} \cdot \mathrm{L}^{-1} \cdot \mathrm{min}$ under the conditions used. The third experiment examined the effect of application frequency at a CT of 3.75 $\mathrm{mg} \cdot \mathrm{L}^{-1} \cdot \mathrm{min}$, which was previously determined to be compatible with select woody perennial species. Three and five applications per week resulted in reduced liverwort growth and fecundity.
\end{abstract}

Marchantia polymorpha L., a common thalloid liverwort, is a significant weed species in nursery and greenhouse operations across North America and Europe, being particularly problematic in propagation houses where the environmental conditions maintained for newly established potted plants are ideal for rapid liverwort establishment (Svenson et al., 1997) (Note: for the purposes of this article, the term liverwort refers only to the species $M$. polymorpha). Liverwort reproduces sexually through spore formation and asexually through tissue fragmentation and the production of gemmae, clonal fragments produced in specialized structures called gemma cups (Altland et al., 2003; Svenson

Received for publication 13 Oct. 2011. Accepted for publication 17 Jan. 2012.

Financial support was provided by the Ontario Centres of Excellence (OCE) and the Ontario Ministry of Agriculture Food and Rural Affairs (OMAFRA).

We thank Ping Zhang for her statistical advice and periodic weekend watering. We also thank Laura Greenway-Balnar and Dave Greenway for the use of their ozone dissolution systems. We are grateful to Michael Stasiak, Richard Cote, and Melanie Millington for their insight and critical review of the manuscript.

The research presented is a component of the corresponding author's $\mathrm{PhD}$ thesis.

Mention of a trademark, proprietary product, or vendor does not constitute a guarantee or warranty of the product by the author(s) or the University of Guelph and does not imply its approval to the exclusion of other products or vendors that also may be suitable.

${ }^{1}$ To whom reprint requests should be addressed; e-mail tgraham@uoguelph.ca. et al., 1997). Combined, these reproductive strategies enable the rapid distribution and development of liverwort on the surface of nursery container growth substrates (Fig. 1).

In potted plant production, liverwort infestations present a clear impediment to water and nutrient infiltration (Fig. 1), thereby reducing the growth and value of the crop (Svenson et al., 1997). This diversion results in higher water and fertilizer demands, which translates to greater production costs, reduced productivity, and environmental impacts in the form of excessive water taking and increased nutrient discharge from the production facility.

A heavy liverwort infestation also provides a habitat for other pests and potential pathogens such as fungus gnats (Bradysia spp. Sciaridae), snails (e.g., Helix spp.), slugs (e.g., Deroceras spp.), and a host of microbial threats such as Fusarium spp. and Pythium spp. (Svenson et al., 1997). Additional costs to control these pests, combined with production losses resulting from their activity, further erode profit margins.

Impacts of a significant liverwort infestation (on profit margins) continue to be realized once a potted crop reaches marketable size. The presence of liverwort is considered unsightly and often taken as an indication of reduced quality or plant vigor, all of which impact the final valuation of the crop.

A significant amount of research has been conducted to evaluate chemical compounds for the control of liverwort (Newby, 2006). Svenson et al. (1997) provide a list of compounds purported to have some efficacy in the control of liverwort. Although potentially effective under prescribed conditions, many of the listed chemicals are not registered for liverwort control. Lack of registered control products leaves growers with few options beyond hand removal.

Hand removal is a costly method of weed control by any measure and can increase the unit cost of production dramatically. Estimates put the cost of supplemental hand weeding (not exclusive to liverwort) at \$1235-\$9880 per ha (Case et al., 2005; Judge et al., 2004). In addition to the direct labor costs associated with hand removal, the physical removal of weeds also removes a portion of the upper layer of substrate (including surface-applied slow-release fertilizer), thereby damaging roots in the upper segment of the pot. The cost of hand removal and the impacts that the practice has on substrate structure and root vigor necessitates continued effort to develop alternative control strategies.

Dissolving highly reactive ozone $\left(\mathrm{O}_{3}\right)$ gas in irrigation solutions (ozonation) is an emerging agricultural water remediation technology that has garnered favor on both environmental and operational efficacy grounds. Ozone is a highly effective antimicrobial agent while also being reactive with many chemical contaminants that may be present in irrigation source water. Furthermore, in a time when organic markets are outpacing traditional agricultural commodity markets, with organic products commanding significant price premiums (Kendrick, 2008), ozone is one of the few disinfection options compatible with organic production methods and certification bodies. Ozone's acceptance as an organically compatible intervention technology is based largely on the fact that there are no ozone residuals remaining on the crop after application. Residual ozone (not consumed as a part of the treatment) spontaneously reverts to diatomic oxygen $\left(\mathrm{O}_{2}\right)$ in a complex process that further enhances the antimicrobial effect.

This study has focused on aqueous ozone $\left[\mathrm{O}_{3(\mathrm{aq})}\right]$ (in the context of this study, aqueous ozone refers to water that retains a residual ozone concentration) as a potential component of an overall liverwort management program when the technology (ozonation system) is already used as an irrigation water remediation tool. Aqueous ozone has a long history of water and wastewater treatment applications and in recent years has also gained some momentum as an irrigation water treatment technology in nursery and greenhouse production (Ehret et al., 2001; Graham et al., 2009; McDonald, 2007). Operators that use ozonation as a component of their irrigation water treatment system tend to use it in batch format. The water is treated with ozone and stored in tanks to allow the residual ozone to revert to $\mathrm{O}_{2}$. Alternatively, the solutions are passed through filters that break down the residual ozone.

The removal of the ozone before distribution to the crop provides an opportunity for re-inoculation of the solution from biofilms found on the distribution system hardware. The removal of the disinfecting agent also disallows any potential for in situ pathogen control through direct ozone contact with 


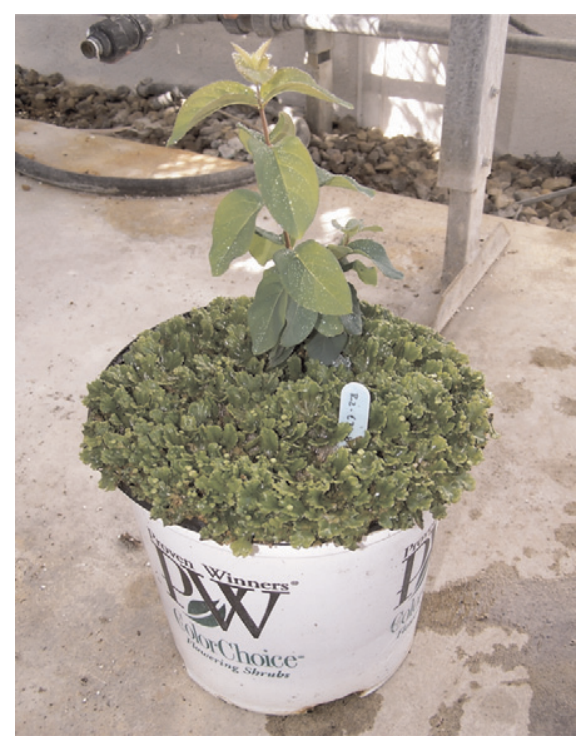

Fig. 1. An example of severe liverwort infestation in container nursery stock. Liverwort mats on the substrate surface interfere with water and nutrient penetration while providing habitat for pests and disease vectors.

pathogen vectors on the plant or growth substrate surfaces.

Justifiable prudence prompts the removal of ozone from irrigation solutions as ozone (gas) phytotoxicity is well established (Ashmore, 2005). Tropospheric ozone enrichment (photochemical smog) elicits phytotoxic reactions in a wide array of plant species over a range of concentrations (Bell and Treshow, 2002). Although phytotoxic, recent studies suggest that under conditions of controlled application in aqueous solution, ozone can be safely applied (foliar and directly to substrate) to select horticultural crop species (Fujiwara and Fujii, 2002; Graham et al., 2009, 2011; OhashiKaneko et al., 2009; Sloan and Engelke, 2005). There is also limited evidence that ozone application to the root zone can improve some plant performance metrics (Graham et al., 2011; Sloan and Engelke, 2005). The capacity to safely retain residual ozone in the irrigation solution during distribution to the crop is significant in that it may allow for the control of pests/pathogens throughout the irrigation system and may in fact have some efficacy in the control of pests at the plant/pot level (Fujiwara and Fujii, 2002).

Marchantia polymorpha (and thalloid liverworts in general) are distinctive within the plant kingdom in that they do not possess the stomatal machinery (guard cells) to actively regulate gas exchange between the bulk atmosphere and the thallus interior (Green and Snelgar, 1982). In place of a functional stomatal complex, liverwort has a pore structure that is a largely unregulated diffusion pathway. It is reasonable to surmise that this restricted capacity to regulate gas exchange would result in a greater flux of pollutant gases relative to plants fully capable of regulating gas exchange. If this is the case, then liverwort should exhibit a greater negative growth response to an application of ozone (gaseous or aqueous) with all else being equal (i.e., no speciesspecific unique antioxidant systems). It is on this premise that these studies were based.

The objectives of the presented studies were to: 1) examine contact time (concentration multiplied by the time of exposure) as a process control parameter for liverwort management; 2) establish initial aqueous ozone toxicity thresholds for liverwort; and 3) evaluate the response of liverwort to aqueous ozone at exposure levels and application frequencies that are consistent with the tolerance thresholds of select woody perennial nursery species established previously (Graham et al., 2009).

\section{Materials and Methods}

Plant material propagation. Liverwort samples were collected from a nursery operation in Southern Ontario (St. Thomas, Ontario, Canada; long. 42 $47^{\prime} 58^{\prime \prime} \mathrm{N}$, lat. $81^{\circ} 12^{\prime} 52^{\prime \prime} \mathrm{W}$ ) and brought to the University of Guelph (Guelph, Ontario, Canada; long. $43^{\circ} 33^{\prime} \mathrm{N}$, lat. $80^{\circ} 15^{\prime} \mathrm{W}$ ) for propagation. The samples were separated into sections $\approx 5 \mathrm{~cm}^{2}$ and evenly (5-cm spacing) placed onto mineral wool propagation sheets (Grodan Inc., Milton, Ontario, Canada). The transplants were then placed on a propagation misting bed and kept between 18 and $22{ }^{\circ} \mathrm{C}$ under 400 -W high-pressure sodium lights that delivered $90-100 \mathrm{umol} \cdot \mathrm{m}^{-2} \cdot \mathrm{s}^{-1}$ at the tissue surface. The tissue was misted with deionized water (until wet) every $30 \mathrm{~min}$ during the 14-h photoperiod. Misting frequency was reduced to once every hour during the dark $(10 \mathrm{~h})$ period. The transplants were fertilized with a modified Voth \#5 solution (Voth, 1943) twice daily by misting (hand sprayer) until the surface of the tissue was wet. After a 5- to 7-d establishment period (tissue anchored to media by newly formed rhizoids), the regular fertilizer regime was supplemented with a $5 \mathrm{~mm} \mathrm{Ca}\left(\mathrm{NO}_{3}\right)_{2}$ solution three times per week.

Experimental unit preparation. Apical sections of liverwort $\approx 1 \mathrm{~cm}^{2}$ were excised from the propagated parent material. Sets of four segments were selected, photographed against a white background with a scale and experimental unit ID clearly visible, then arranged radially on a $7 \mathrm{~cm} \times 7 \mathrm{~cm} \times 2-\mathrm{cm}$ block of mineral wool (Gro-Slab Expert 20/77 A2W; Grodan Inc.). The block was pre-soaked in deionized water for $1 \mathrm{~h}$ followed by a soaking in a 1:10 dilution of a modified Voth \#5 solution. The populated blocks were then placed on a misting bed for $14 \mathrm{~d}$ (Expts. 1 and 2) or $7 \mathrm{~d}$ (Expt. 3) before treatment initiation, during which rhizoid formation secured the individual segments to the mineral wool blocks. The blocks were misted with a fullstrength modified Voth \#5 solution twice daily during the establishment period and once daily during the treatment period.

Aqueous ozone preparation. Aqueous ozone is unstable and as such, solutions were prepared at the time of treatment application. Tap water $\left(17-21^{\circ} \mathrm{C}\right)$ was fed into a mass transfer loop (Shaw Mixer ${ }^{\mathrm{TM}}$; Purification Research
Technologies Incorporated, Guelph, Ontario, Canada) running at loop pressure of 206.8 $\mathrm{kPa}$. The system impinged ozone gas, through a venturi injector (Mazzei 584, Bakersfield, CA) on the irrigation water stream. The ozone gas used in the mass transfer loop was generated by passing ambient air through an oxygen concentrator (Workhorse-8 5665; SeQual Technologies Inc., San Diego, CA) that removed the majority of the nitrogen from the air stream, passing the concentrated oxygen $\left(90 \%\right.$ to $\left.95 \% \mathrm{O}_{2}\right)$ through to a corona discharge ozone generator (1500P; Clearwater Tech LLC, San Luis Obispo, CA). Excess ozone (not dissolved) in the system flowed to the top of the loop where it was discharged to an off-gas destruct unit (OCD11; Clearwater Tech LLC).

Aqueous ozone application. To achieve a stable ozone exposure regime, a dunking system was constructed in which the experimental units could be submerged for the prescribed time period. The assembly consisted of a bottom-fed reservoir connected to the output of the mass transfer system. In the first two trials, the system was set up as an overflow reservoir that would continuously deliver the ozone-containing solution to the bottom of a 2.5 -L reservoir, where it would flow up past the experimental units (two units treated at a time) and out over a spillway. In this system, the ozone generator was set to fixed outputs that provided relatively stable ozone concentrations in the treatment stream. In the third trial, the system was expanded and automatic feedback control was added. The reservoir was enlarged to $50 \mathrm{~L}$ and a mixing port was incorporated into the bottom feed. The mixing port consisted of a $15-\mathrm{cm}$ length of $2.5-\mathrm{cm}$ diameter polyvinyl chloride pipe with $0.8-\mathrm{mm}$ holes drilled in a radial pattern along the length of the pipe. This allowed for good mixing of the input solution within the reservoir. A secondary stream of the mixed solution was taken off the reservoir and directed to a dissolved ozone monitor (Q45H; Analytical Technologies Inc., Collegeville, PA). The monitor was equipped with an output feedback control loop that was tuned to maintain the bulk solution at the ozone set point $\left(0.5 \mathrm{mg} \cdot \mathrm{L}^{-1}\right)$. A submersion platform was also added to the system to allow all 14 experimental units to be treated at the same time.

Three separate experiments (Expts. 1, 2, and 3) were conducted. The first two experiments were conducted to determine if contact time was suitable as a control parameter when the objective is to control a plant pest rather than a microbial pathogen. Expt. 1 modulated the concentration at a fixed exposure time, whereas Expt. 2 held the ozone concentration constant while modulating the exposure time. Expt. 3 was designed to evaluate liverwort response to application frequency at CTs previously determined to be acceptable for woody perennial production (Graham et al., 2009).

Expt. 1. This experiment was set up as a completely randomized design (CRD) with six treatment levels and 10 experimental 
units per treatment $(n=10)$. Treatment allocation on the CRD grid was determined using IRRISTAT software (International Rice Research Institute, Los Baños, Philippines). Individual experimental units were assigned at random to each position on the grid using a random number series (http://www.Random. org). The treatments consisted of a 30-s exposure to solutions with $\left[\mathrm{O}_{3(\mathrm{aq})}\right]$ of $0.0 \mathrm{mg} \cdot \mathrm{L}^{-1}$, $0.5 \mathrm{mg} \cdot \mathrm{L}^{-1}, 1.5 \mathrm{mg} \cdot \mathrm{L}^{-1}, 2.5 \mathrm{mg} \cdot \mathrm{L}^{-1}, 3.5 \mathrm{mg} \cdot \mathrm{L}^{-1}$, and $5.0 \mathrm{mg} \cdot \mathrm{L}^{-1}$, which translated to contact times of $0,0.25,0.75,1.25,1.75$, and 2.50 $\mathrm{mg} \cdot \mathrm{L}^{-1} \cdot \mathrm{min}$, respectively. The treatments were applied for 5 consecutive days, after which a 2-d recovery period was provided before harvesting the tissue. Total thallus area $\left(\mathrm{cm}^{2}\right)$ was measured with a leaf area meter (LI-3100C; LI-COR, Lincoln, NE) and dry weight was measured with a standard analytical balance (TE124S; Sartorius AG, Goettingen, Germany) after the representative samples had reached a constant dry weight at $65^{\circ} \mathrm{C}$.

Expt. 2. This experiment was also set up as a CRD with six treatment levels and 10 experimental units per treatment. The treatments consisted of exposures for 0,30 , $45,60,75$, and $90 \mathrm{~s}$ to a $2.0-\mathrm{mg} \cdot \mathrm{L}^{-1} \mathrm{O}_{3(\mathrm{aq})}$ solution, which translated into contact times of $0,1.0,1.5,2.0,2.5$, and $3.0 \mathrm{mg} \cdot \mathrm{L}^{-1} \cdot \mathrm{min}$, respectively. The layout and experimental unit allocation were conducted as described in Expt. 1. The treatments were applied for 5 consecutive days, after which a 2-d recovery period was provided. At this stage, five units from each treatment were randomly selected for harvest $(n=5)$. The remaining five experimental units were allowed to grow for an additional $7 \mathrm{~d}$ before harvesting $(\mathrm{n}=5)$ to determine how well liverwort would recover from the treatments. Total thallus area and dry weight were measured as in Expt. 1 for each harvest period. Additionally, the chlorophyll content index (CCM-200; Opti-Sciences, Hudson, NH) was measured.

Expt. 3. A factorial treatment design $(2 \times 3$; $\mathrm{n}=14$ ) was used for this experiment with $\mathrm{O}_{3(\mathrm{aq})}$ concentration and frequency of application as treatment factors. There were two levels of $\mathrm{O}_{3(\mathrm{aq})}$ concentration $\left(0.0 \mathrm{mg} \cdot \mathrm{L}^{-1}\right.$ and $0.5 \mathrm{mg} \cdot \mathrm{L}^{-1}$ ) and three frequency levels (one, three, and five applications per week). All treatment applications were $7.5 \mathrm{~min}$ in duration and the treatments were maintained for $28 \mathrm{~d}$. Treatment order on any given day was randomized first by $\mathrm{O}_{3(\mathrm{aq})}$ concentration and then by frequency of application. During treatment application, all experimental units were removed from the growth system and transported to the treatment facility to minimize variations arising from periodic exposure to different environmental regimes. In addition to the metrics already described for Expts. 1 and 2, the following parameters were also quantified.

Gemma cup count. The total gemma cups present at treatment initiation and treatment termination were counted. A $4 \times$ magnifying lens was used during the count so as to include primordial cups (i.e., initiated but not fully developed) in the total count.
Gemmae counts, average size, total area. After the final treatment application, all experimental units were thoroughly rinsed to remove as many gemmae as possible from their cups. The plants were then returned to the growth facility for $4 \mathrm{~d}$ to allow gemmae recovery. After $4 \mathrm{~d}$, each block was inverted and placed on a filter disk (7.0-cm diameter Q5 quantitative disk; Fisher Scientific, Pittsburgh, PA) moistened with deionized water. Slight pressure was applied to the block, after which it was lifted and rotated a quarter turn and returned to the filter disk. The process was repeated until a complete rotation was made. The blotted filter disk was then placed in a petri dish and photographed against a black background with a scale present in the field of view. The disks were then wetted with 300 $\mu \mathrm{L}$ of a modified Voth \#5 solution, covered, and placed on the factorial grid in the same position that the mineral wool block was removed from. The digital images were analyzed (average size, total area, and total number) using the "analyze particles" macro in Image J at a threshold set point of 64:125 (Rasband, 1997-2011).

Removal force. The strength and degree with which liverwort binds to the growth substrate influences how much media is removed and how much crop root disturbance could occur during hand removal. The maximum resistive force experienced during the removal of the tissue from the mineral wool block was measured with a force gauge (9812FG-20KG; Control Company, Friendswood, $\mathrm{TX})$. The gauge was connected to the thallus tissue through a fork inserted between the thallus tissue and the mineral wool. The tissue sample was secured to a stable surface and the force gauge was lifted, through a scissor-lift, until the tissue released from the mineral wool. The force gauge recorded the maximum force experienced during the procedure.

Statistical analysis. For Expts. 1 and 2, one-way analysis of variance (ANOVA) with a Dunnett's post-test and regression analysis was performed using GraphPad Prism (Version 5.0d for Mac; GraphPad Software, San Diego, CA). All error bars on individual means are reported as the SEM. Regression error bands are reported as the $95 \%$ confidence interval (CI). Where necessary, the data were transformed to meet the requirements of the analysis and the analysis was conducted on the transformed data but is presented in original format for clarity.

Data from Expts. 1 and 2 were used to determine if contact times from different combinations of time and concentration had the same effect on liverwort development. The data were normalized to account for differences in starting values and regressions were made to compare the slopes and elevations between the two.

For Expt. 3, a two-way ANOVA with a Bonferroni post-test was conducted and complimented by regression analysis. Error bars are reported as the SEM for individual means and as the $95 \%$ CI for regressions.

\section{Results}

Expt. 1. The results of Expt. 1 are summarized in Figure 2. Both thallus area and dry
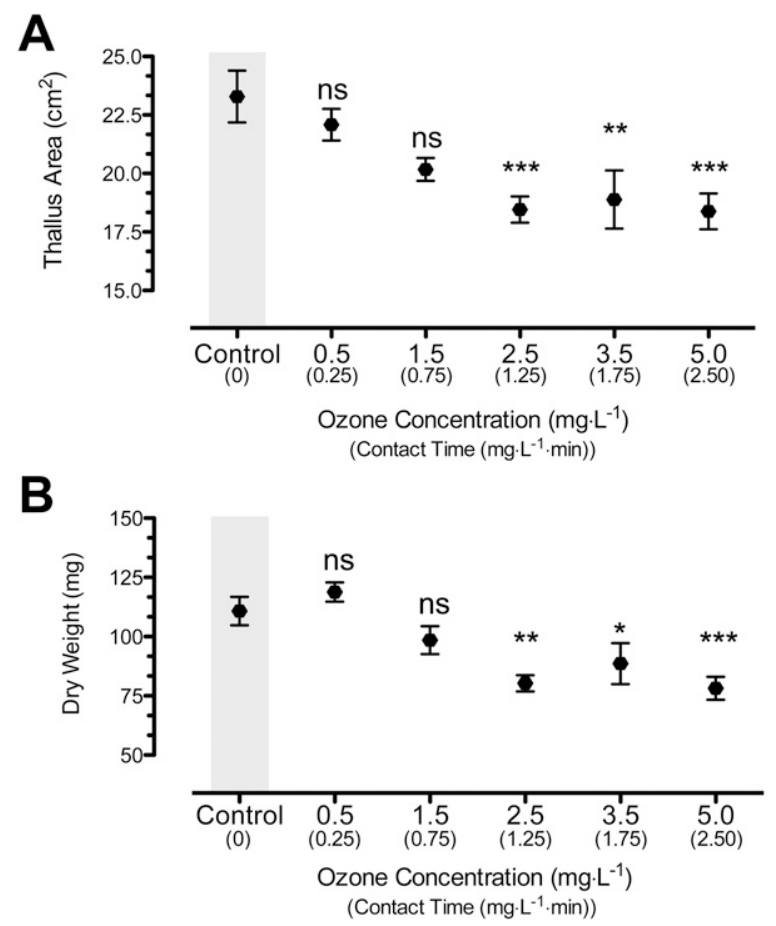

Fig. 2. Liverwort thallus area (A) and dry weight (B) accumulation after five consecutive daily applications of aqueous ozone (30-s daily exposure at six aqueous ozone concentrations) followed by a 2-d recovery period. The ozone treatments are compared with the control using analysis of variance with a Dunnett's post-test. Ns, ${ }^{*}, * *, * * *$ Nonsignificant or significant at $P \leq 0.05,0.01$, or 0.001 , respectively; error bars are \pm SE. 
matter accumulation were reduced by the treatments beginning at $\mathrm{CT} 1.25 \mathrm{mg} \cdot \mathrm{L}^{-1} \cdot \mathrm{min}$ when compared with the control.

Expt. 2. Figure 3 summarizes the thallus area and chlorophyll content response to the ozone treatments. In this experiment, thallus area response was inconclusive (Fig. 3A-B); however, chlorophyll content (Fig. 3C-D) and dry matter accumulation (Fig. 4) exhibited significant negative responses to the application of aqueous ozone. The suppression in dry matter accumulation was uniform across all the ozone treatments (excluding control) and continued through to Day 14, a full $9 \mathrm{~d}$ after treatment cessation (Fig. 4).

Contact time evaluation. The data from Expts. 1 and 2 were corrected for differences in starting dry weights and compared by regression analysis. There were no significant differences for the two data sets $\left(\mathrm{p}_{\text {slope }}=\right.$ $0.2369 ; p_{\text {elevation }}=0.4250$ ) and as such, the data were pooled and an overall regression was performed. Based on that regression analysis (Fig. 5), a toxic threshold CT range was established between CT $0.84 \mathrm{mg} \cdot \mathrm{L}^{-1} \cdot \mathrm{min}$ and CT $1.68 \mathrm{mg} \cdot \mathrm{L}^{-1} \cdot \mathrm{min}$, which corresponds to a $50 \%$ to $75 \%$ reduction in dry matter accumulation, a reduction we consider representative of a response equating to liverwort control. This range is well below the tolerable CT values reported elsewhere for crop species (Graham et al., 2009; Sloan and Engelke, 2005).

Expt. 3. The results of Expt. 3 are summarized in Figures 6 through 10. The response of liverwort to the two extreme treatment regimes is presented in Figure 6. The zero ozonelow-frequency treatment (Fig. 6) shows healthy tissue with ample gemma cups, whereas the ozone-high-frequency application shows significant browning and general tissue damage (Fig. 6). Thallus area and dry matter accumulation analysis (Fig. 7) confirmed the negative impact on liverwort growth. The degree of suppression increased with the frequency at which the tissue was exposed to aqueous ozone (Fig. 7).

Gemma cups and gemmae production are summarized in Figure 8A-F. Both cup (Fig. 8A) and individual gemma (Fig. 8D-F) production was reduced by the application of aqueous ozone ( $\mathrm{p}_{\text {cups }}<0.0001 ; \mathrm{p}_{\text {gemma }}<$ $0.0001)$ relative to the non-ozonated samples. The degree of reduction also increased with the frequency of ozone application $\left(\mathrm{p}_{\text {cups }}=\right.$ $\left.0.0001 ; p_{\text {gemma }}=0.0195\right)$. The non-ozonated tissue had uniform counts (cups and gemmae) regardless of the application frequency (Fig. 8A and D). In addition to reducing the number of cups produced, the ozone treatments damaged the cups (Fig. 8B-C). The damage is severe and may impact the ability for water droplets to penetrate the cup structure and dislodge any viable gemmae.

Gemmae size was significantly reduced by aqueous ozone $\left(\mathrm{p}_{\text {day } 01}<0.0001 ; \mathrm{p}_{\text {day } 07}=\right.$ $0.0004)$ and the degree of suppression was also dependent on application frequency $\left(\mathrm{p}_{\text {day } 01}=\right.$ $0.0002 ; p_{\text {day } 07}=0.0005$ ) (Fig. 9). The average size of the gemmae that received ozone treatments was consistently smaller than the control

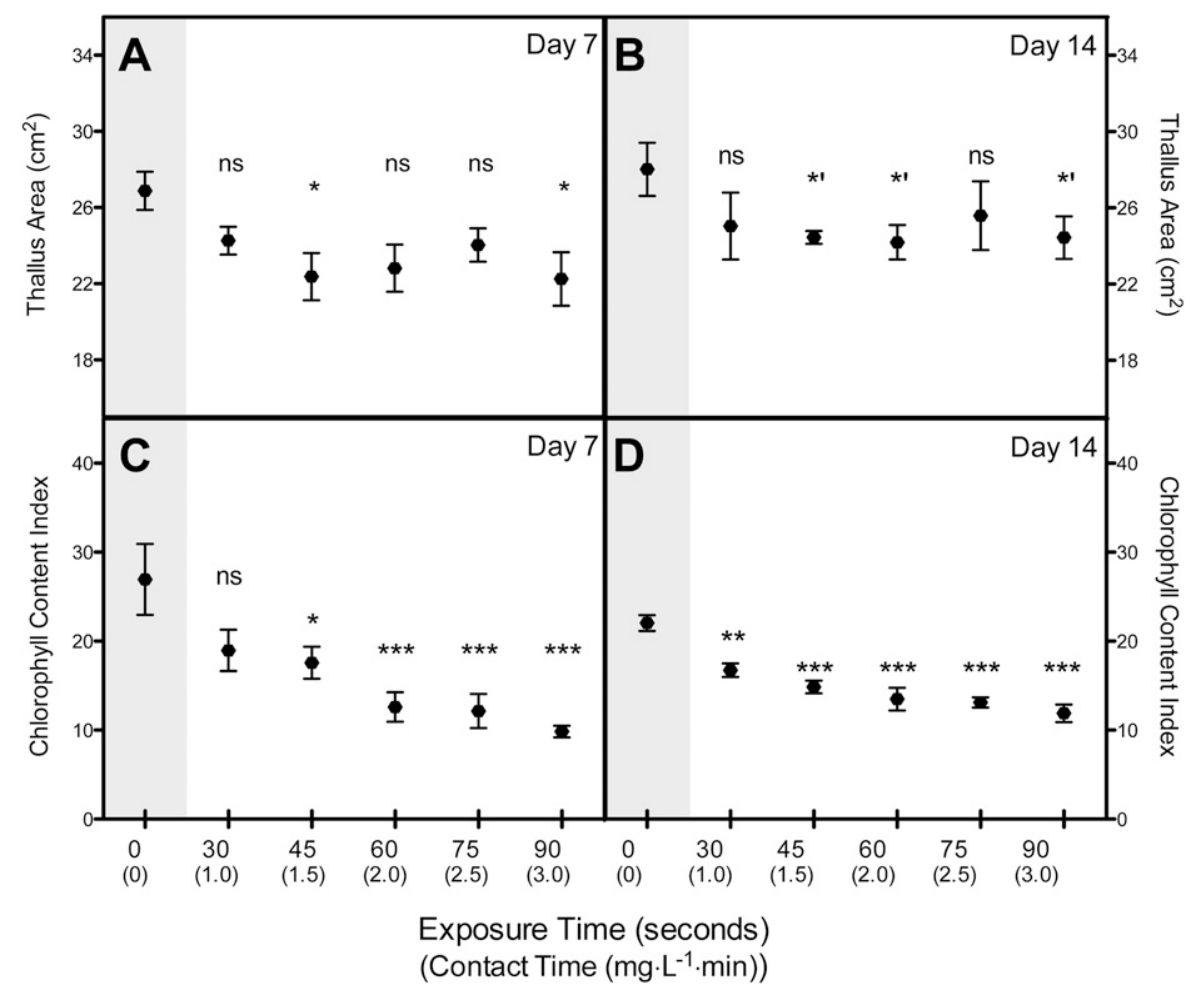

Fig. 3. Expt. 2 parameter summary: (A) liverwort thallus area accrued after 5 consecutive days of treatment followed by a 2-d recovery period; (B) after $9 \mathrm{~d}$ recovery. (C) Liverwort chlorophyll content index after 5 consecutive days of treatment followed by a 2-d recovery period; (D) after $9 \mathrm{~d}$ recovery. Where comparisons are followed by ('), the means were compared using and unrestricted $t$ test in place of the Dunnett test. Ns, * **, $* * *$ Nonsignificant or significant at $P \leq 0.05,0.01$, or 0.001 , respectively; error bars are $\pm \mathrm{SE} ; *$ unrestricted comparisons.

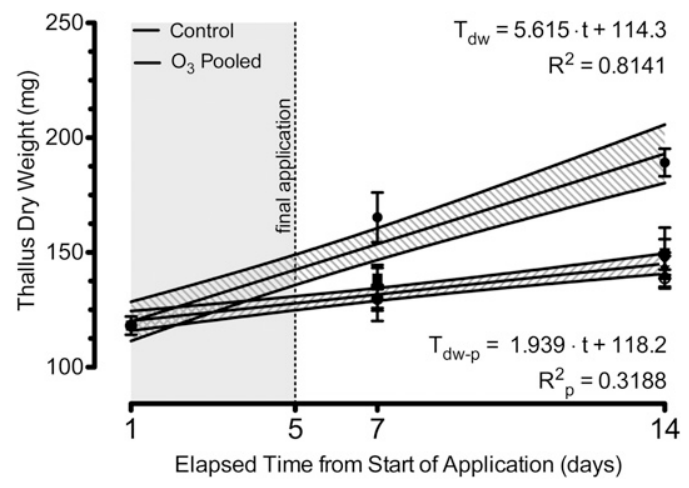

Fig. 4. Liverwort thallus dry weight response to aqueous ozone exposure. A summary of the regression analysis conducted for Expt. 2. All non-control ozone treatments were pooled (after individual slope comparison) and a single response relationship presented in comparison with the control regression line. $\left(\mathrm{T}_{\mathrm{dw}}=\right.$ thallus dry weight; $\mathrm{T}_{\mathrm{dw}-\mathrm{p}}=$ thallus dry weight - pooled. $)$ Error bars on individual means are \pm $\mathrm{SE}$; error bars on the regression models are $\pm 95 \%$ confidence interval.

treatments at all application frequencies (Figs. 9A, C and D). There were also significant reductions in gemma size within both concentration regimes as application frequency increased (Fig. 9A). The growth of gemmae after treatments stopped was not significantly different when examined proportionally (percentage increase in size) (data not shown); however, the difference in absolute growth (average size of gemmae at Day 7) was very significant $(P<$ $0.0001)$ as demonstrated in Figures 9B, E, and F.

The force required to remove the thallus tissue from the mineral wool blocks was significantly reduced by the ozone treatment
$(P=0.0009)$ and application frequency $(P<$ 0.0001) (Fig. 10). At an ozone application frequency of five times per week, the removal force was significantly reduced compared with the non-ozone treatment at five applications per week as well as compared with the other ozone treatments at lower application frequencies (Fig. 10).

\section{Discussion}

The presented study was predicated on the assumption that ozone-containing water is applied directly to nursery or greenhouse 


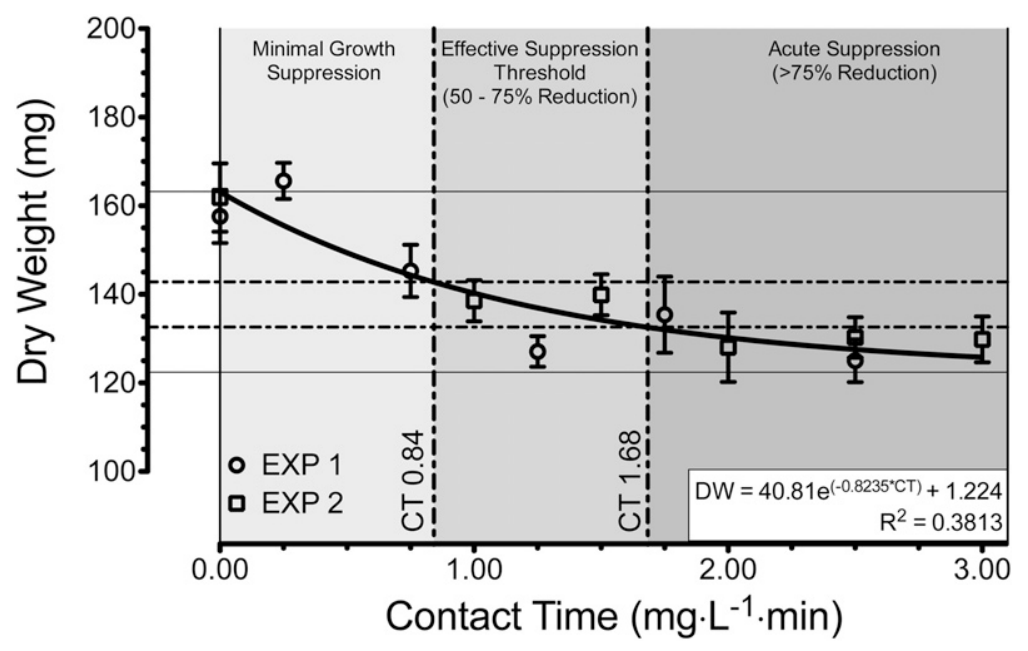

Fig. 5. Data from Expt. 1 and the first harvest of Expt. 2 were compared with regression analysis. After a correction for initial dry mass differences, the data were pooled and a best-fit relationship established. Vertical dashed lines = contact time damage threshold limits $(50 \%$ to $75 \%$ reduction in dry mater accumulation). Horizontal solid lines = upper and lower limits of the regression model. Horizontal dashed lines $=$ theoretical dry matter levels representing $50 \%$ and $75 \%$ reduction over the theoretical maximum dry weight. Error bars are \pm SE.

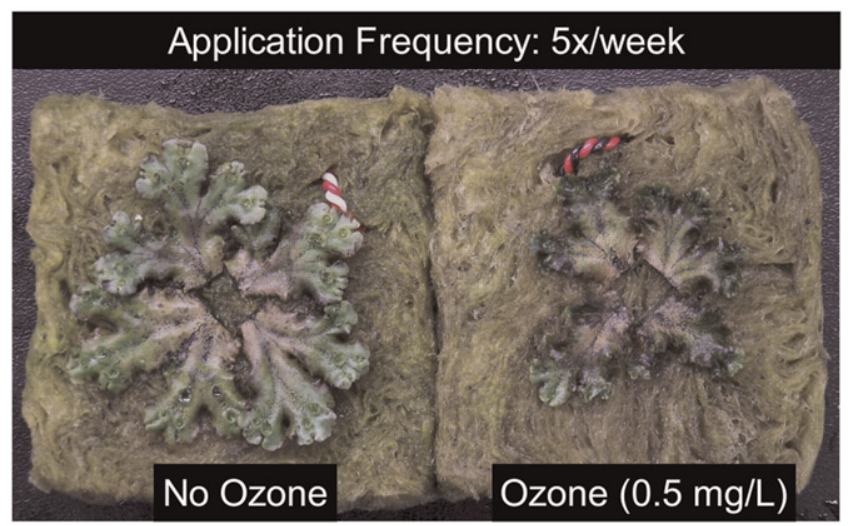

Fig. 6. Visual comparison of liverwort suppression using aqueous ozone. The experimental units illustrated were both subjected to five treatments per week. The unit on the left was treated with tap water, whereas the unit on the right was exposed to tap water containing $0.5 \mathrm{mg} \cdot \mathrm{L}^{-1}$ aqueous ozone.

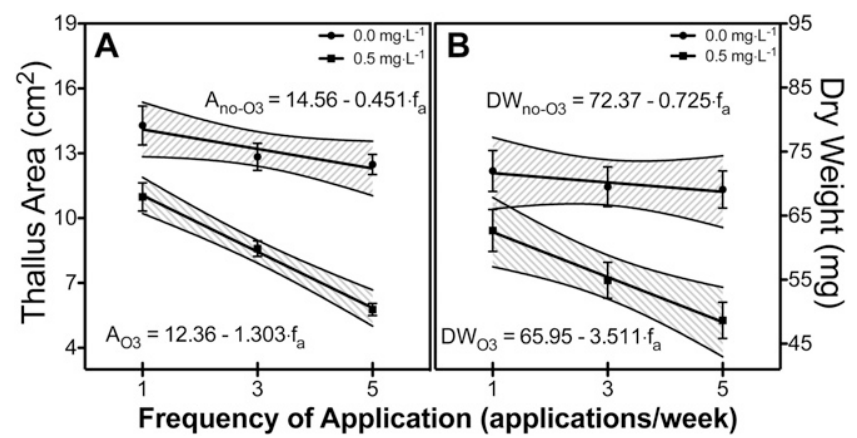

Fig. 7. Summary of Expt. 3 liverwort thallus area (A) and dry weight (B) response to aqueous ozone treatments $\left(0.0\right.$ or $0.5 \mathrm{mg} \cdot \mathrm{L}^{-1}$ for $\left.7.5 \mathrm{~min}\right)$ applied at three frequencies (one, three, and five times per week) over $28 \mathrm{~d} . \mathrm{f}_{\mathrm{a}}=$ frequency of application; $\mathrm{A}=$ thallus area; $\mathrm{DW}=$ thallus dry weight; error bars on individual means are $\pm \mathrm{SE}$; error bars on the regression models are $\pm 95 \%$ confidence interval.

crops and that through direct application ancillary benefits such as liverwort control may be realized. However, ozonation as an irrigation water treatment technology is often overlooked despite its widespread use in other water treatment applications (Rice, 1999). The oversight is likely the result of well-established phytotoxicity data for ozone gas as a component of photochemical smog (Ashmore, 2005). Operators that have installed ozonation systems typically remove the ozone before use, thereby mitigating any risks. The removal is prudent given the paucity of data supporting any other course of action. This does, however, limit the effectiveness of the ozone treatment and opens the door for re-inoculation.

A small but mounting body of research has emerged over the last decade to shed scientific light on irrigation water management strategies involving ozone. Key developments include demonstrations of nutrient stability and improved plant productivity. Graham (2002), and more recently OhashiKaneko et al. (2009), demonstrated that nutrient ions are largely unaffected by the addition of ozone, the exception being iron and manganese, which can precipitate during treatment.

Sloan and Engelke (2005), and more recently Graham et al. (2011), demonstrated that ozone-containing water applied directly to growth substrates could elicit small stimulatory effects in creeping bentgrass and hydroponic tomato, respectively. Sloan and Engelke (2005) suggest that the effect is associated with enhanced nutrient mineralization, whereas Graham et al. (2011) further suggest that increased oxygen in the root zone may also play a role.

Graham et al. (2009) demonstrated that foliar application of ozone-containing water is feasible. In that study, ozone-containing water (up to $1.5 \mathrm{mg} \cdot \mathrm{L}^{-1}$ at the emitter) did not negatively impact plant productivity or cause visible damage in select woody perennials. The authors did note that off-gas was a concern in overhead irrigation systems and safeguards should be in place to ensure safe conditions for the crop and workers alike. These cautions are reiterated here. Before ozone can be used in a plant pest control application, the control parameters need to be reconciled with the desired outcomes. Expts. 1 and 2 confirm (Figs. 2 to 5) CT as a valid process control parameter. This being said, the CT realized at the crop or plant pest level will differ from that experienced by pathogens in the bulk solution. Measuring the residual ozone concentration and knowing the system residence time will give accurate values for bulk CTs; however, if a solution is being sprayed, then the CT realized at the crop will be impacted by pressure changes, drop size, etc. (Fujiwara and Fujii, 2004; Graham et al., 2009). Failure to account for these variables would result in unsatisfactory system performance.

Expt. 3 demonstrated that treatments with ozone-containing water, at concentrations safe for select perennial nursery species (Graham et al., 2009), can reduce liverwort development under the conditions examined (Figs. 6 and 7). Equally, if not more importantly, the study clearly demonstrated a suppression of liverwort asexual fecundity (Figs. 8 and 9). Ozone treatments reduced the number and size of the gemmae (Figs. 8A, D-F and 9), and although some viable gemmae were observed under the highest frequency and concentration regime (Fig. 8D), development was delayed (Fig. 9). Ozone treatments also damaged the gemma cup structure (Fig. 8BC), which could impact the ability of water 


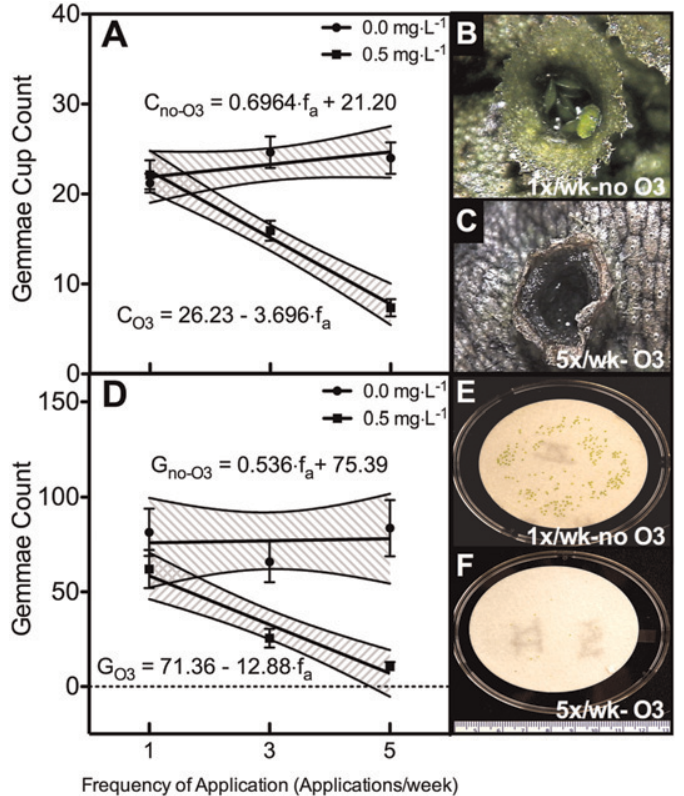

Fig. 8. Liverwort gemma cup and gemmae production in response to the aqueous ozone treatments. (A) Gemma cup development in response to ozone treatments; (B) healthy gemma cup with gemmae bodies present (magnification $40 \times$ ); (C) distorted gemma cup as a result of aqueous ozone applications (magnification 40×); (D) gemmae production in response to aqueous ozone applications; (E) gemma blot from healthy thallus tissue; (F) gemma blot from thallus tissue exposed to aqueous ozone at an application frequency of $5 \times$ per week. $\mathrm{f}_{\mathrm{a}}=$ frequency of application; $\mathrm{C}=$ cup count; $\mathrm{G}=$ gemmae count Error bars on individual means are $\pm \mathrm{SE}$; error bars on the regression models are $\pm 95 \%$ confidence interval.

A

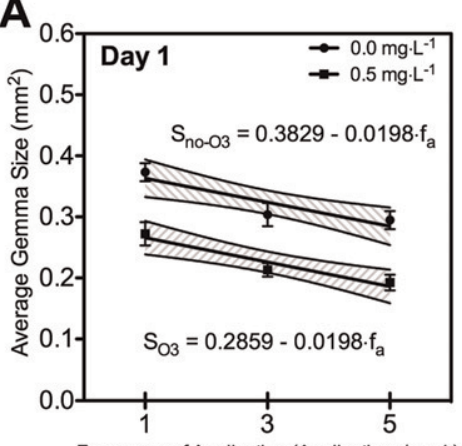

Frequency of Application (Applications/week)

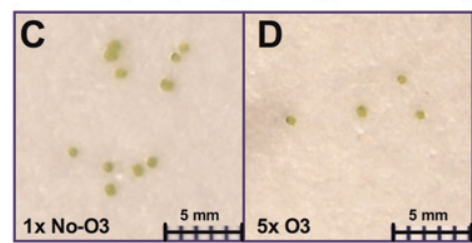

B
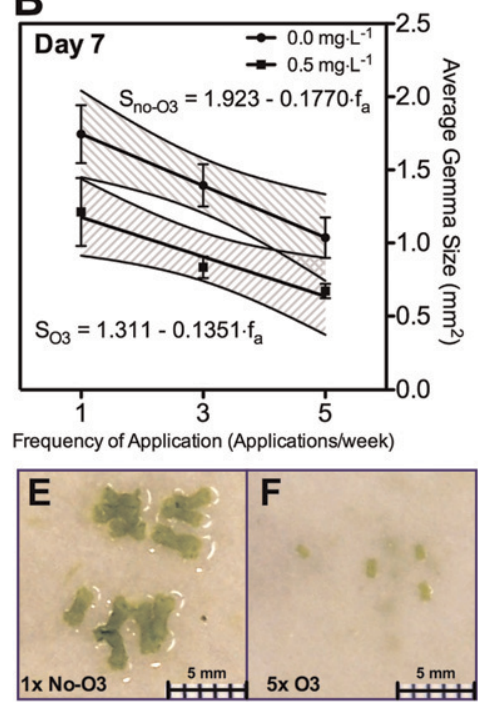

Fig. 9. Summary of gemmae development after cessation of treatments. (A) Gemmae size at the time of transfer to filter disks; (B) Gemmae size after 7-days growth; (C) representative Day 1 selection of gemmae from the $0.0 \mathrm{mg} \cdot \mathrm{L}^{-1}$ —one application per week treatment; (D) representative Day 1 selection of gemmae from the $0.5 \mathrm{mg} \cdot \mathrm{L}^{-1}$ - five applications per week treatment; (E) representative Day 7 selection of gemmae from the $0.0 \mathrm{mg} \cdot \mathrm{L}^{-1}$ —one application per week treatment; $(\mathbf{F})$ representative Day 7 selection of gemmae from the $0.5 \mathrm{mg} \cdot \mathrm{L}^{-1}$ - five applications per week treatment. $\mathrm{f}_{\mathrm{a}}=$ frequency of application; $\mathrm{S}=$ gemmae size; Error bars on individual means are $\pm \mathrm{SE}$; error bars on the regression models are $\pm 95 \%$ confidence interval.

droplets to penetrate the cup and dislodge any viable gemmae, further reducing the potential for dissemination.

Increasing application frequency reduced gemma size regardless of ozone concentration (Fig. 9). The treatment protocol tended to dislodge mature gemmae, which likely con- tributed to the observed size reductions. Although the frequency of application influenced the size of gemmae, overall the gemmae from ozone-treated liverworts were smaller and less numerous that the non-ozone treatments (Figs. 8 D-E and 9A-B). Furthermore, application frequency had no effect on

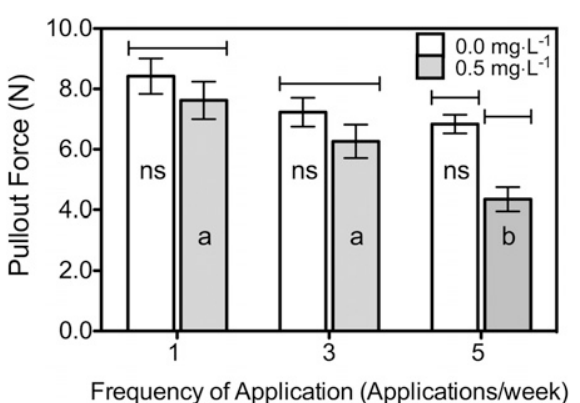

Fig. 10. Liverwort removal force summary. The average maximum resistive force (newtons) recorded for each treatment regime during the removal of the thallus tissue from the mineral wool growth substrate. Vertical bars within a single frequency level covered by the same horizontal line do not differ at $P \leq 0.05$. Vertical white bars $\left(0.0 \mathrm{mg} \cdot \mathrm{L}^{-1}\right)$ do not differ from one another at $P \leq 0.05$. Vertical shaded bars with the same letter do not differ at $P \leq 0.05$. Error bars are \pm SE.

gemma cup numbers or total gemmae produced unless ozone was present, in which case there was a strong reduction (Fig. 8).

Expt. 3 also demonstrated that ozone treatments reduced the force required to remove thallus tissue (Fig. 10). Given that hand removal is still a common control strategy, the use of aqueous ozone could reduce labor costs and root damage by reducing the substratebinding force that the liverwort exerts.

Frequency of application is another parameter that needs to be well characterized if a control system is to prove effective and offer flexibility to the grower (i.e., matching watering frequency and pest control requirements). The results presented suggest that a minimum of three treatments in a 7-d cycle (ongoing) is required to achieve moderate control with an application frequency of five times per 7-d cycle providing strong control (Figs. 6 to 10).

The presented data support the eventual incorporation of ozone-containing irrigation solutions into an overall liverwort management strategy. The use of these ozone-containing solutions for liverwort management is ancillary to the overall objectives of currently installed ozonation systems, which are primarily disease management in the bulk solution. The study provides baseline application frequencies and CTs required for liverwort control. This said, the study is not representative of, nor should the results be extrapolated to, commercial operational conditions. The lack of background data necessitated tight control over, and high repeatability in, actual liverwort aqueous ozone exposure. This in turn necessitated the use of a dosing system that, although effective at controlling the exposure and providing the requisite repeatability, is not practical for commercial deployment. What the study does provide, in conjunction with other literature cited, is a background for the development of field trials that would confirm or refute these bench scale results. These field trials would also prove useful in elucidating the pre- and 
post-emergence liverwort management efficacy of aqueous ozone. Extended field trails will be pivotal if ozone-based irrigation water treatment is to move from a batch process incapable of systemwide disinfection or direct plant protection to an in-line process capable of greatly expanded disinfection roles as well as a host of other ancillary benefits.

\section{Conclusions}

Contact time appears to be a suitable process control parameter for the regulation of aqueous ozone systems applied to liverwort management. A minimum CT of 0.84 $\mathrm{mg} \cdot \mathrm{L}^{-1} \cdot \mathrm{min}$ is required for control; however, this will vary depending on the nature of the application system. Pre-production trials should be conducted under operational conditions before a hard CT control target is set.

Aqueous ozone has been demonstrated to reduce the growth of liverwort as well as reduce the fecundity of the tissue that survives within the limits of crop $\mathrm{O}_{3(\mathrm{aq})}$ tolerance. Therefore, the maintenance of a small residual $\mathrm{O}_{3(\mathrm{aq})}$ concentration during distribution of irrigation water to the crop has the potential to offer some level of liverwort control.

The question mark at the end of the title to this article is intended to stimulate a scientific exploration of ancillary applications of aqueous ozone used in irrigation water management, applications such as liverwort control. The presented study does not fully answer the question posed; rather, it provides a framework from which to expand the knowledge base.

\section{Literature Cited}

Altland, J., J. Regan, and A. Newby. 2003. Liverwort control in propagation: Challenges and opportunities. Combined Proc. Intl. Plant Propagators' Soc. 53:383-386.

Ashmore, M.R. 2005. Assessing the future global impacts of ozone on vegetation. Plant Cell Environ. 28:949-964.

Bell, J.N.B., and M. Treshow. 2002. Air pollution and plant life. 2nd Ed. Wiley, West Sussex, U.K.

Case, L.T., H.M. Mathers, and A.F. Senesac. 2005. A review of weed control practices in container nurseries. HortTechnology 15:535-545.

Ehret, D., B. Alsanius, W. Wohanka, and J. Menzies. 2001. Disinfestation of recirculating nutrient solutions in greenhouse horticulture. Agronomie 21:323-339.

Fujiwara, K. and T. Fujii. 2002. Effects of spraying ozonated water on the severity of powdery mildew infection on cucumber leaves. Ozone Sci. Eng. 24:463-469.

Fujiwara, K. and T. Fujii. 2004. Effects of ozonated water spray droplet size and distance on the dissolved ozone concentration at the spray target. Ozone Sci. Eng. 26:511-516.

Graham, G.T. 2002. The effects of nutrient solution ozonation on nutrient balance and lettuce production in a recirculating hydroponic system. MSc diss., University of Guelph, Guelph, Ontario, Canada.

Graham, T., P. Zhang, E. Woyzbun, and M. Dixon. 2011. Response of hydroponic tomato to daily applications of aqueous ozone via drip irrigation. Sci. Hort. 129:464-471.

Graham, T., P. Zhang, Y. Zheng, and M. Dixon. 2009. Phytotoxicity of aqueous ozone on five container-grown nursery species. HortScience 44:774-780.
Green, T.G.A. and W.P. Snelgar. 1982. A comparison of photosynthesis in two thalloid liverworts. Oecologia 54:275-280.

Judge, C.A., J.C. Neal, and J.B. Weber. 2004. Dose and concentration responses of common nursery weeds to Gallery. Surflan and Treflan. J. Environ. Hort. 22:106-112.

Kendrick, J. 2008. Organic: From niche to mainstream. Statistics Canada. Catalogue no. 96325-XIE2007000 Canadian Agriculture at a Glance. 6 Dec. 2011.<http://www.statcan.gc.ca/ pub/96-325-x/2007000/article/10529-eng.htm>.

McDonald, G.V. 2007. Ozone (O3) efficacy on reduction of Phytophthora capsici in recirculated horticultural irrigation water. $\mathrm{PhD}$ diss. Texas A\&M, College Station, TX. p. 121.

Newby, A. 2006. Liverwort control in containergrown nursery crops. MSc diss., Auburn University, Auburn, AL.

Ohashi-Kaneko, K., M. Yoshii, T. Isobe, J.-S. Park, K. Kurata, and K. Fujiwara. 2009. Nutrient solution prepared with ozonated water does not damage early growth of hydroponically grown tomatoes. Ozone Sci. Eng. 31:21-27.

Rasband, W.S. 1997-2011. ImageJ. U.S. National Institutes of Health, Bethesda, MD.

Rice, R. 1999. Ozone in the United States of America-State-of-the-art. Ozone Sci. Eng. 21: 99-118.

Sloan, J.J. and M.C. Engelke. 2005. Effect of ozonated water on creeping bentgrass growth in a sand medium. HortTechnology 15:148152.

Svenson, S.E., B. Smith, and B. Briggs. 1997. Controlling liverworts and moss in nursery production. Combined Proc. Intl. Plant Propagators'. Soc. 47:414-422.

Voth, P.D. 1943. Effects of nutrient-solution concentration on the growth of Marchantia polymorpha. Bot. Gaz. 104:591-601. 